\title{
Does gender play a role in functional asymmetry of ventromedial prefrontal cortex?
}

\author{
Daniel Tranel, Hanna Damasio, Natalie L. Denburg and Antoine Bechara
}

Department of Neurology, Division of Cognitive Neuroscience, University of lowa College of Medicine, IA, USA

Correspondence to: Daniel Tranel, PhD, Department of Neurology, University of lowa Hospitals and Clinics, 200 Hawkins Drive, lowa City, IA 52242, USA

E-mail: daniel-tranel@uiowa.edu

We found previously in a lesion study that the right-sided sector of the ventromedial prefrontal cortices (VMPCs) was critical for social/emotional functioning and decision-making, whereas the left side appeared to be less important. It so happened that all but one of the subjects in that study were men, and the one woman did not fit the pattern very well. This prompted a follow-up investigation, in which we explored the following question: Does gender play a role in the development of defects in social conduct, emotional functioning and decision-making, following unilateral VMPC damage? We culled from our Patient Registry same-sex pairs of men or women patients who had comparable unilateral VMPC damage in either the left or right hemisphere. Two male pairs and one female pair were formed, and we included two additional women with unilateral right VMPC damage (8 patients in all). The domains of measurement covered social conduct, emotional processing and personality, and decision-making. We found a systematic effect of gender on the pattern of left-right asymmetry in VMPC. In men, there were severe defects following unilateral right VMPC damage, but not following left-sided damage. In women, there were defects following unilateral left VMPC damage; following right-sided damage, however, defects were mild or absent. The findings suggest that men and women may use different strategies to solve similar problems-e.g. men may use a more holistic, gestalt-type strategy, and women may use a more analytic, verbally-mediated strategy. Such differences could reflect asymmetric, gender-related differences in the neurobiology of left and right VMPC sectors.

Keywords: sex differences; frontal lobes; emotion; personality; decision-making

Abbreviations: IGT = lowa gambling task; MMPI-2 = Minnesota Multiphasic Personality Inventory-2; SCR = skin conductance response; VMPC = ventromedial prefrontal cortex; WAIS-III = Wechsler Adult Intelligence Scale, Third Edition.

Received June 6, 2005. Revised August 22, 2005. Accepted August 30, 2005. Advance Access publication September 29,2005

\section{Introduction}

In a previously reported lesion study, we found that the rightsided sector of the ventromedial prefrontal cortices (VMPCs) was critical for social functioning, emotional processing and personality, and decision-making, whereas the left side appeared to play a less important role (Tranel et al., 2002). It so happened that all but one of the subjects in this study were men, and the one woman did not fit the pattern very well. In a recent functional imaging study, it was found that men generated more right-sided prefrontal activation during a decision-making task, whereas women generated more left-sided prefrontal activation (Bolla et al., 2004). Thus, the question arises as to whether there might be gender-related differences in the manner in which prefrontal brain structures mediate functions related to social and emotional processing, and decision-making. Specifically, in men the right-sided VMPC sector (but not the left) might be critical for these functions, whereas in women, the left-sided VMPC sector (but not the right) might be critical. If this is true, then unilateral damage to the right VMPC should lead to defects in social/emotional functioning and decision-making in men, but not in women, and unilateral damage to the left VMPC should lead to the opposite outcome, i.e. defects in women but not in men. The current study describes a preliminary test of these predictions and presents intriguing evidence suggesting gender-related functional asymmetry of the VMPC.

\section{Methods \\ Participants}

The participants were selected from the Patient Registry in the Division of Cognitive Neuroscience at the University of Iowa, under the auspices of which the patients have undergone extensive screening and comprehensive characterization of neuropsychological 
functioning (Tranel, in press) and neuroanatomical status (Damasio and Frank, 1992; Frank et al., 1997). To be eligible for enrolment in the current study, the participants had to have focal, stable lesions that involved the VMPC in either the left or right hemisphere. In accord with the requirements for enrolment in our Patient Registry, the participants had to be free of a history of mental retardation, learning disability, psychiatric disorder or substance abuse. Also, the participants had to be free of histories of abnormal social conduct, emotional maladjustment or other psychological maladies that predated the onset of their brain lesion (in DSM-IV nomenclature, no participant had a pre-lesion history of Axis I or Axis II disorders). The neuropsychological, neuroanatomical and experimental studies were conducted when the participants were in the chronic phase of recovery. For this study, it was important that sufficient time had elapsed between lesion onset and our experimental measurements to allow for potential changes in personality, social status and occupational functioning to become manifest. Hence, we studied the participants several years after lesion onset (the degree of 'chronicity' ranged from 3 to 20 years; see Table 1 ).

For the purposes of this study, the VMPC was defined as the region that encompasses the medial orbital sector and the lower medial prefrontal sector. We searched our Patient Registry with the objective of identifying pairs of men and women who had comparable VMPC lesions, one on the left and one on the right. That is, for each pair, one patient would have a left VMPC lesion, and the other patient (of the same sex) would have a right VMPC lesion that was comparable in location and extent of damage (see below). The search turned up three such matches, two male pairs and one female pair (six patients in all). We also found two additional women patients with right-sided VMPC lesions, who did not have perfect left-sided female matches but who were of interest to compare with the men patients. The decision to include these two women was also motivated by the fact that women are underrepresented in extant lesion studies of unilateral VMPC function. In fact, the notion that unilateral right VMPC damage can lead to deficits in social/ emotional functioning and decision-making has already been supported in male subjects in several studies (Rolls et al., 1994; Hornak et al., 1996; Angrili et al., 1999; Blair and Cipolotti, 2000; Tranel et al., 2002; Gomez-Beldarrain et al., 2004). These studies, however, have a remarkable paucity of female participants (see Discussion section), and thus the question of how unilateral VMPC damage affects social/emotional functioning and decision-making in women remains very much unexplored. In short, we felt there were compelling reasons to include the additional women cases. Demographic data for the eight participants are provided in Table 1. The table presents the patient pairs as matched on neuroanatomical status (see below) along with the two additional women cases.

\section{Experimental measurement}

Three general domains of function were assessed: social conduct, emotional processing and personality, and decision-making. The specific instruments used to measure aspects of each domain are described below. This approach is modelled on one we used previously for a similar type of assessment (Tranel et al., 2002), and the fundamental measurement instruments are the same as those used in our previous study (the reader is referred to that study for a more complete description of the testing procedures).

\section{Social conduct}

The domain of social conduct covered parameters of social status, employment status and interpersonal functioning, with the aim of establishing whether or not the patient had undergone a post-morbid change in overall social functioning. Structured rating scales completed by clinicians (clinical neuropsychologists who were naïve as to the hypotheses and objectives of the current study), family members and close friends were used to make determinations about change in social conduct. For Social Status, change was defined as an alteration in the patient's financial security or in peers' judgement of the patient's social attainment. For Employment Status, change was defined as an alteration in the patient's procurement or level of occupation (e.g. inability to sustain gainful employment). For Interpersonal Functioning, change was defined as an alteration in the patient's ability to sustain normal social relationships with significant others such as family and friends. (It should be clear that change, in all cases, was in the negative direction; in no case did a patient demonstrate improvement in these functions following their brain lesion.)

\section{Emotional processing and personality}

Emotional processing and personality were measured with several standardized and experimental procedures. The participants received the Beck Depression Inventory (BDI) and Minnesota Multiphasic Personality Inventory-2 (MMPI-2) during the course of their

Table I Demographic data

\begin{tabular}{|c|c|c|c|c|c|c|c|c|}
\hline Participants & Sex & $\begin{array}{l}\text { Lesion: } \\
\text { hemisphere }\end{array}$ & Age & $\begin{array}{l}\text { Education } \\
\text { (years) }\end{array}$ & Handedness* & Chronicity $^{\dagger}$ & $\mathrm{VIQ}^{\ddagger}$ & $\mathrm{PIQ}^{\ddagger}$ \\
\hline $\begin{array}{l}1652 \\
1589\end{array}$ & $\begin{array}{l}\text { Male } \\
\text { Male }\end{array}$ & $\begin{array}{l}\text { Left } \\
\text { Right }\end{array}$ & $\begin{array}{l}44 \\
51\end{array}$ & $\begin{array}{l}11 \\
18\end{array}$ & $\begin{array}{r}+60 \\
+100\end{array}$ & $\begin{array}{l}10 \\
19\end{array}$ & $\begin{array}{r}96 \\
126\end{array}$ & $\begin{array}{l}94 \\
98\end{array}$ \\
\hline $\begin{array}{l}0297 \\
1768\end{array}$ & $\begin{array}{l}\text { Male } \\
\text { Male }\end{array}$ & $\begin{array}{l}\text { Left } \\
\text { Right }\end{array}$ & $\begin{array}{l}51 \\
62\end{array}$ & $\begin{array}{l}16 \\
12\end{array}$ & $\begin{array}{l}+100 \\
+100\end{array}$ & $\begin{array}{l}20 \\
10\end{array}$ & $\begin{array}{r}110 \\
95\end{array}$ & $\begin{array}{l}97 \\
92\end{array}$ \\
\hline $\begin{array}{l}2748 \\
2025\end{array}$ & $\begin{array}{l}\text { Female } \\
\text { Female }\end{array}$ & $\begin{array}{l}\text { Left } \\
\text { Right }\end{array}$ & $\begin{array}{l}33 \\
52\end{array}$ & $\begin{array}{l}12 \\
16\end{array}$ & $\begin{array}{r}+90 \\
+100\end{array}$ & $\begin{array}{r}3 \\
10\end{array}$ & $\begin{array}{l}112 \\
113\end{array}$ & $\begin{array}{l}105 \\
116\end{array}$ \\
\hline $\begin{array}{l}1801 \\
2310\end{array}$ & $\begin{array}{l}\text { Female } \\
\text { Female }\end{array}$ & $\begin{array}{l}\text { Right } \\
\text { Right }\end{array}$ & $\begin{array}{l}54 \\
74\end{array}$ & $\begin{array}{l}14 \\
12\end{array}$ & $\begin{array}{l}+100 \\
-100\end{array}$ & $\begin{array}{l}9 \\
3\end{array}$ & $\begin{array}{r}104 \\
93\end{array}$ & $\begin{array}{l}95 \\
98\end{array}$ \\
\hline
\end{tabular}

*Handedness, measured with the modified Oldfield-Geschwind questionnaire that yields scores ranging from full right-handedness (+ 100$)$ to full left-handedness $(-100)$.

${ }^{\dagger}$ Chronicity $=$ time since lesion onset that data were collected, in years.

‡VIQ and PIQ are verbal and performance IQ scores from the WAIS-III, respectively. 
neuropsychological evaluations. In addition, the Iowa Rating Scales of Personality Change ('Iowa Scales') were utilized. The Iowa Scales provide a quantitative measurement of changes in emotional functioning and personality that can become manifest as a consequence of brain injury. The information for the Iowa Scales is acquired from a collateral, i.e. parent, spouse or other family member with regular, extensive contact with the patient. The collateral rates the patient on aspects of emotional functioning, behavioural control, social and interpersonal behaviour, real-world decision-making and insight. The current level of such characteristics is recorded, along with the extent to which the level of each characteristic has changed subsequent to the onset of brain injury. This information is used to assess whether the patient meets the criteria for 'acquired sociopathy', a syndrome typified by: (i) general dampening of emotional experience; (ii) poorly modulated emotional reactions; (iii) disturbances in decision-making, especially in the social realm; (iv) disturbances in goal-directed behaviour; (v) a striking lack of insight into these personality changes. The classification of acquired sociopathy using the Iowa Scales has been addressed in previous work (Barrash et al., 2000; Tranel, 2002; Anderson et al., in press; Koenigs and Tranel, in press), and we followed the same procedures in the current study. The severity of acquired sociopathy in each participant was rated on a 1-2-3 scale, where $1=$ mild, $2=$ moderate and $3=$ severe, by a clinical neuropsychologist familiar with the instrument and blind to the group status of the participants and the hypotheses of the current study.

\section{Decision-making}

The Iowa gambling task (IGT; Bechara et al., 1994) was used to measure decision-making. This task provides a close analogue to real-world decision-making in the manner in which it factors in reward, punishment and uncertainty. The IGT has been used extensively in previous work in our laboratory and many others (e.g. Bechara et al., 2000; Bowman et al., 2005). We obtained behavioural data, which entailed the number of selections from 'advantageous' versus 'disadvantageous' decks of cards during the IGT, and psychophysiological data, which entailed the nature of 'anticipatory' skin conductance responses (SCRs) generated immediately before each card selection, during the time the participant is making their decision of which deck to choose. Based on the behavioural and psychophysiological data, the IGT performance of each participant was classified as 'impaired' or 'normal' using our usual criteria (see Bechara et al., 2000). Briefly, impaired meant that the participant (i) selected significantly more cards from disadvantageous decks than from advantageous ones and (ii) failed to generate anticipatory SCRs to the disadvantageous decks; normal meant that the participant (i) selected significantly more cards from advantageous decks than from disadvantageous ones and (ii) generated anticipatory SCRs to the disadvantageous decks. The magnitude of impairment was rated by one of the authors (A.B., who was blinded to the sex and group status of the participants he was rating) on a 1-2-3 scale, where $1=$ mild, 2 = moderate and $3=$ severe, using a combination of the behavioural data (card selections) and psychophysiological data (SCRs).

\section{Neuroanatomical data quantification and analysis}

The neuroanatomical analysis was based on computerized axial tomography (CT) data in six of the eight cases, because of the nature of the neurological damage, specifically, ruptured aneurysms that were subsequently clipped. The scans were obtained in a Picker 1200 scanner, or in a Toshiba Express SX scanner with various tilts (so as to avoid as much as possible the artefact produced by the aneurysm clips), with a zoom of 2.4, field of $51 \mathrm{~cm}$, a fovea of $212.5 \mathrm{~mm}$, and slice thickness that varied between 2 and $4 \mathrm{~mm}$. In two of the subjects, magnetic resonance scans were possible. These were obtained in a $1.5 \mathrm{~T}$ General Electric scanner with an SPg sequence, in thin $(1.5 \mathrm{~mm})$ contiguous $\mathrm{T}_{1}$ weighted coronal slices. All lesions were manually transferred into a normal reference brain using the MAP-3 technique (Damasio, 2000). The prefrontal region was subdivided into 10 'cells' as depicted in Fig. 1. The cells are numbered 1-10. The VMPC sector corresponds to cells 1-4, numbered in posterior-to-anterior sequence; cell 5 corresponds to the antero-mesial superior sector; cells 6-9 correspond to the lateral orbital sector, again in a posterior-to-anterior sequence; and cell 10 corresponds to an anterior superior dorsolateral sector. For each subject, the percentage involvement (the amount of the cell that is lesioned) in each of these cells was calculated using Brainvox capabilities (Damasio and Frank, 1992; Frank et al., 1997). The lesion data are presented in Fig. 2 and Table 2.

\section{Results}

We did not observe any systematic differences in basic demographic variables in the case pairs (Table 1). Most of the patients were middle-aged; most had at least a high school education; all had average to above average intellectual functioning as measured by the WAIS-III and all but one were right-handed. Data for all of the participants for the outcomes regarding social conduct, emotional functioning and personality, and decision-making, are provided in Tables 3 and 4. (The dependent measures reported in this study do not, as a rule, lend themselves to statistical analysis, and we did not attempt to perform statistical comparisons. Accordingly, the results are presented descriptively, commensurate with the nature of the measurements.) Lesion information with respect to the percentage involvement in each of the designated prefrontal cells is presented in Table 2 .

\section{Anatomical and behavioural results Effect of lesion side, within gender}

Comparison of two men with ventral lesions. This contrast involved case 1652, who has a left ventral VMPC lesion, and case 1589, who has a right ventral VMPC lesion (Fig. 2; Table 2). In both cases the damage is centred in the midsection of the medial orbital region. The involvement of the critical cells (those corresponding to VMPC) is similar with a slight posterior shift for 1589 (the right hemisphere case). The left hemisphere case (1652) was normal in social conduct, emotional processing and personality, and decision-making. He was able to return to his job as a grain elevator worker following his neurological injury (caused by subarachnoid haemorrhage due to rupture of an anterior communicating artery aneurysm) and remains successfully employed there. He continues in a long and stable marriage and functions socially at the same level he did prior to his brain lesion. His MMPI-2 profile is normal, he does not have acquired 

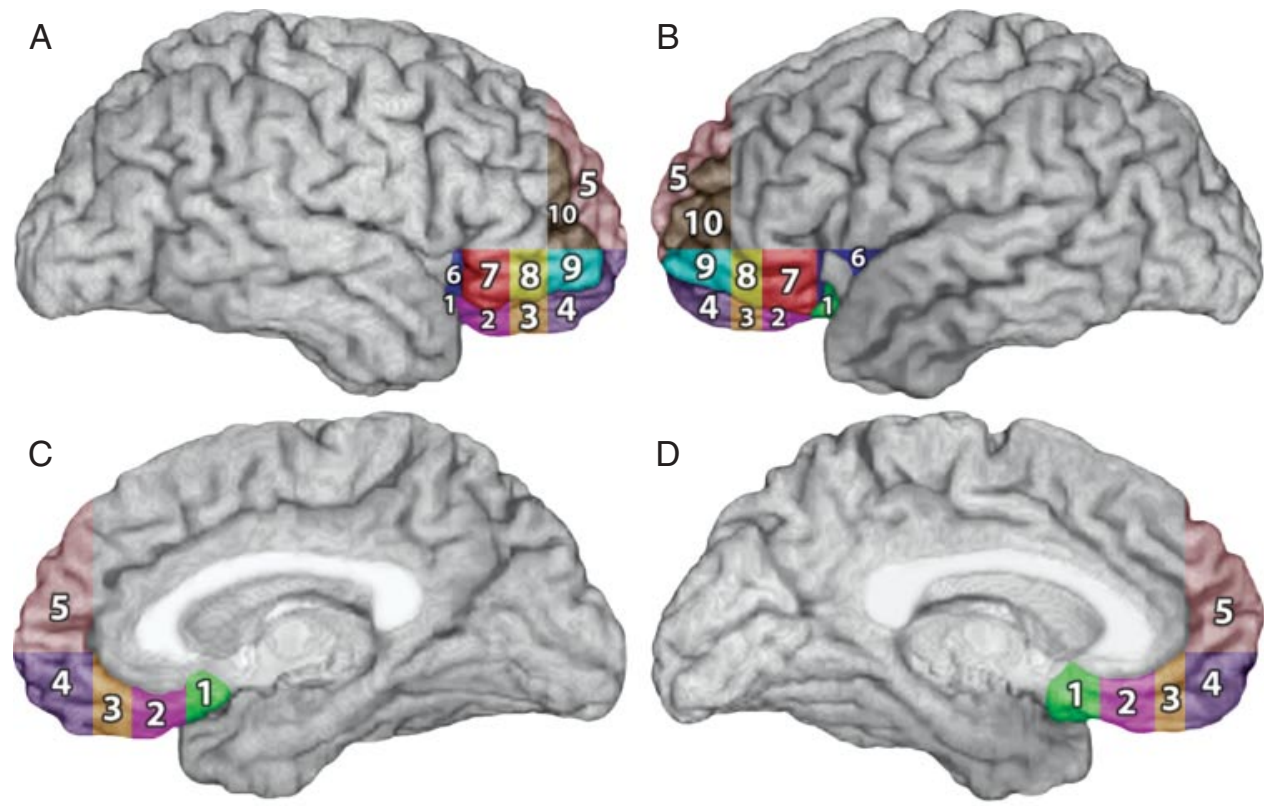

$\mathrm{E}$

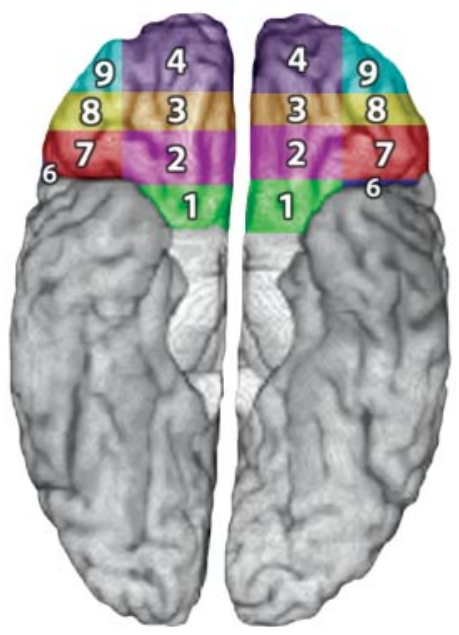

$\mathrm{F}$

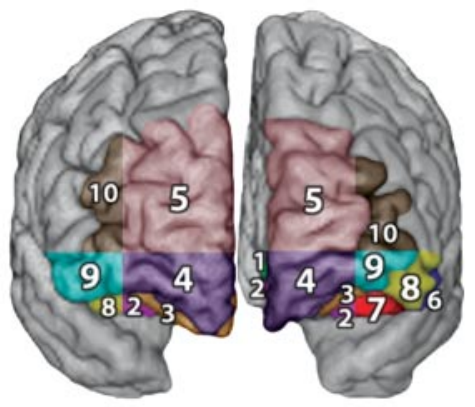

Fig. I Subdivisions of the orbital and medial frontal lobe. Cells I-10 were obtained using the following principles: (A) a plane passing through the superior frontal sulcus perpendicular to the horizontal plane containing anterior commissure-posterior commissure (AC-PC plane) provided the separation into medial and dorsolateral sectors; (B) another plane, parallel to the AC-PC plane and touching the lower edge of the beak of the corpus callosum, separated the orbital sector; (C) the lateral and mesial aspects of this orbital sector were separated by the continuation of the plane described in (A); (D) the anterior-posterior subdivisions of the orbital sector were obtained by coronal planes perpendicular to the AC-PC plane, drawn at the anterior-most edge of the cingulate sulcus and the anterior edge of the corpus callosum (creating the polar region and the anterior middle region); (E) the region behind the middle anterior sector was divided into two halves, a posterior middle and a posterior region; $(\mathbf{F})$ the subdivisions in the lateral orbital sector were obtained as in (D) and (E). Cells I-4 = VMPC sub-regions; posterior; middle posterior; middle anterior and anterior, respectively. Cell $5=$ medial superior. Cells 6-9 = lateral orbital sub-regions; posterior, middle posterior, middle anterior and anterior, respectively. Cell $10=$ anterior dorsolateral.

sociopathy, and he performed normally on the IGT. The right hemisphere case (1589), by contrast, had severe impairments in social conduct, emotional processing and personality, and decision-making. Prior to his lesion (also caused by subarachnoid haemorrhage due to rupture of an anterior communicating artery aneurysm), he worked successfully as a minister and counsellor, but afterwards, he was never able to secure and maintain any kind of gainful employment, and he continues to require regular supervision to execute activities of daily living. He had an abnormal MMPI-2 profile, with significant elevations on the psychopathy (4) and paranoia (6) scales, and he had severe acquired sociopathy and severely impaired performance on the IGT.

Comparison of two men with ventral-mesial lesions. This contrast involved case 0297, who has a left ventral-mesial VMPC lesion, and case 1768, who has a right ventral-mesial VMPC lesion (Fig. 2; Table 2). In both cases the lesion involves most of the VMPC (cells 1-4); in case 1768 it extends into superior mesial territory (cell 5). The involvement of the VMPC cells is similar in the two cases, with slightly larger involvement for 


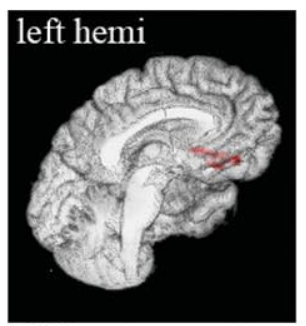

1652

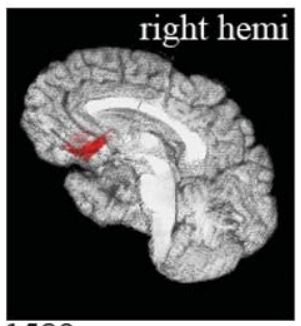

1589

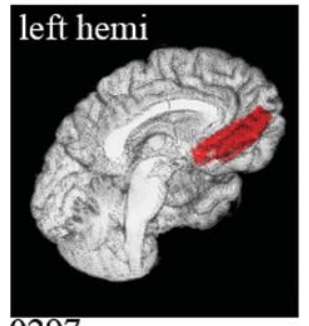

0297

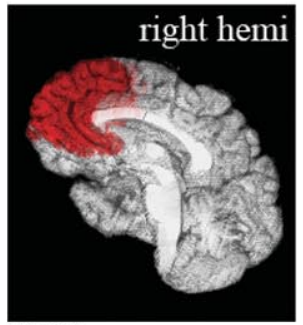

1768
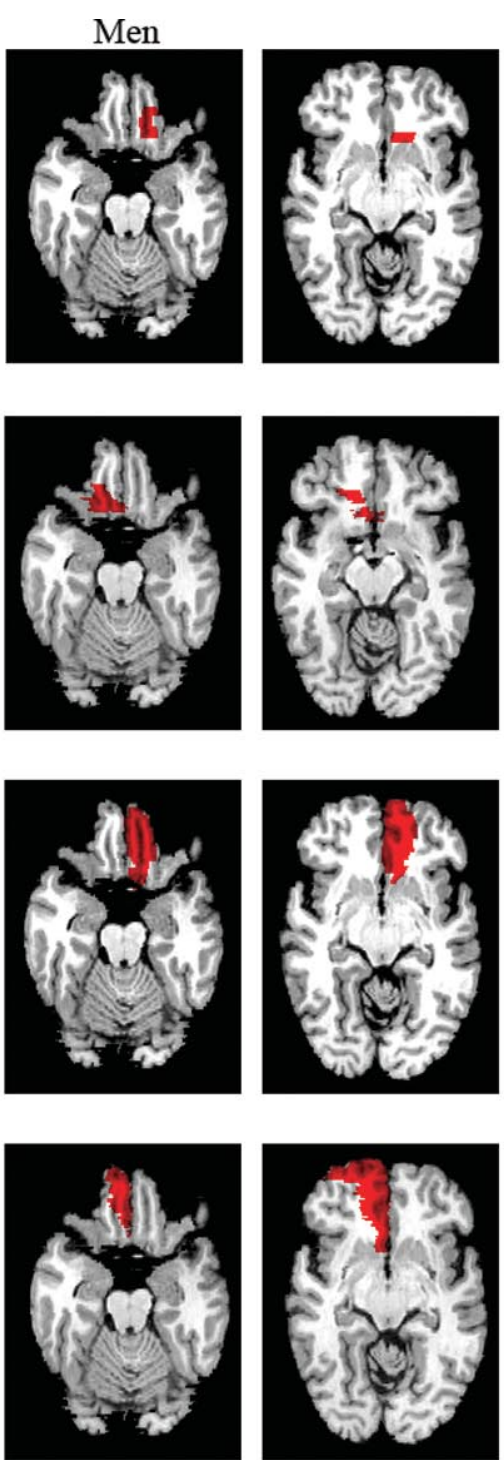

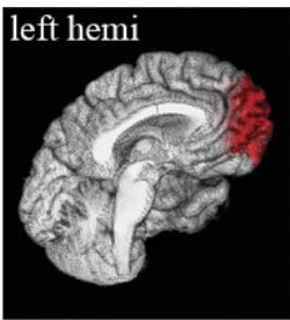

2748

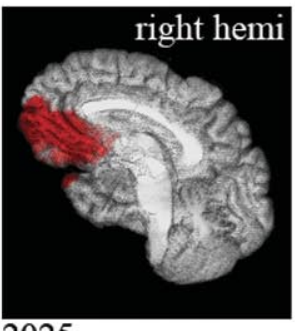

2025

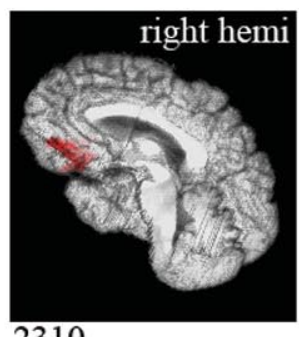

2310

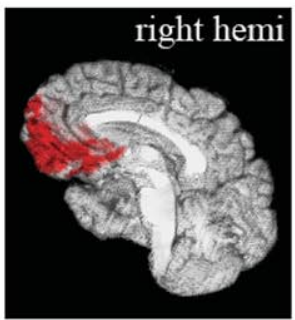

1801
Women
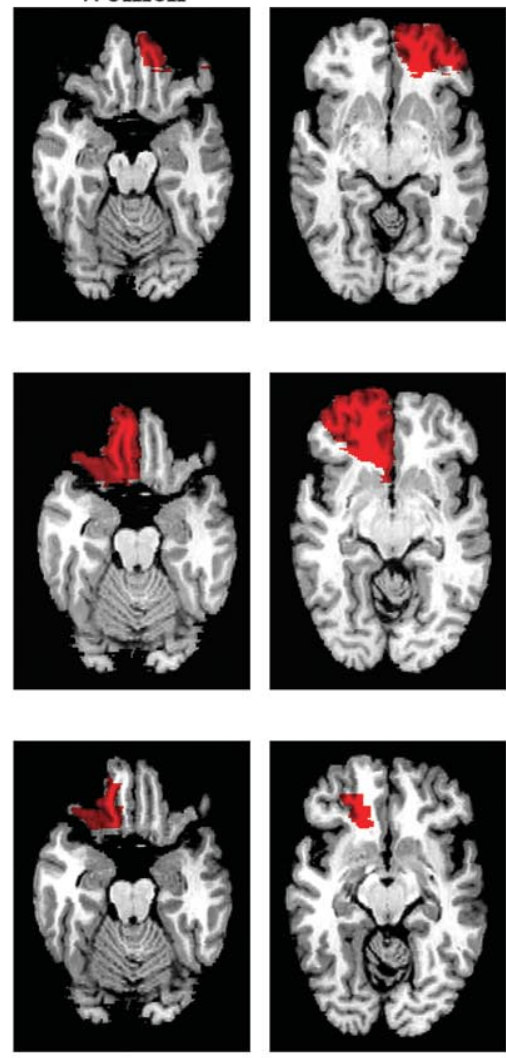

Fig. 2 Depiction of the lesions of the participants after transfer onto a template brain (MAP-3 technique). Four men are on the left side of the figure; four women are on the right side. $\mathrm{R}$ and $\mathrm{L}$ indicate the hemispheres; left is depicted on the right, and right is depicted on the left. Specific case contrasts highlighted in the Results section are I652 versus 1589; 0297 versus 1768; 2748 versus 2025; I589 versus 23I0; 1768 versus 2025 and I80I; and 2748 versus 0297.

Table 2 Percentage involvement of prefrontal cells for each participant

\begin{tabular}{|c|c|c|c|c|c|c|c|c|c|c|c|c|}
\hline Participant & Sex & Hemisphere & Cell I & Cell 2 & Cell 3 & Cell 4 & Cell 5 & Cell 6 & Cell 7 & Cell 8 & Cell 9 & Cell 10 \\
\hline 1652 & $M$ & $\mathrm{~L}$ & 3.07 & 20.39 & 2.18 & 0 & 0 & 0 & 0 & 0 & 0 & 0 \\
\hline 1589 & M & $\mathrm{R}$ & 21.33 & 28.67 & 0.16 & 0 & 0 & 0 & 0 & 0 & 0 & 0 \\
\hline $\begin{array}{l}0297 \\
1768\end{array}$ & $\begin{array}{l}M \\
M\end{array}$ & $\begin{array}{l}L \\
R\end{array}$ & $\begin{array}{l}24.87 \\
\text { I } 5.57\end{array}$ & $\begin{array}{l}49.43 \\
24.46\end{array}$ & $\begin{array}{l}63.12 \\
51.28\end{array}$ & $\begin{array}{l}50.96 \\
79.33\end{array}$ & $\begin{array}{c}0 \\
90.64\end{array}$ & $\begin{array}{l}0 \\
0\end{array}$ & $\begin{array}{l}0 \\
0\end{array}$ & $\begin{array}{l}0 \\
0.01\end{array}$ & $\begin{array}{c}0 \\
25.59\end{array}$ & $\begin{array}{r}2.94 \\
26.27\end{array}$ \\
\hline $\begin{array}{l}2748 \\
2025\end{array}$ & $\begin{array}{l}\mathrm{F} \\
\mathrm{F}\end{array}$ & $\begin{array}{l}L \\
R\end{array}$ & $\begin{array}{c}0 \\
58.11\end{array}$ & $\begin{array}{r}6.79 \\
79.33\end{array}$ & $\begin{array}{l}58.68 \\
92.58\end{array}$ & $\begin{array}{l}76.52 \\
85.67\end{array}$ & $\begin{array}{r}66.90 \\
9.07\end{array}$ & $\begin{array}{l}0 \\
0\end{array}$ & $\begin{array}{r}4.37 \\
14.84\end{array}$ & $\begin{array}{l}76.00 \\
34.81\end{array}$ & $\begin{array}{l}80.12 \\
75.30\end{array}$ & $\begin{array}{l}97.33 \\
10.70\end{array}$ \\
\hline $\begin{array}{l}1801 \\
2310\end{array}$ & $\begin{array}{l}\mathrm{F} \\
\mathrm{F}\end{array}$ & $\begin{array}{l}R \\
R\end{array}$ & $\begin{array}{r}44.56 \\
5.01\end{array}$ & $\begin{array}{l}72.16 \\
33.33\end{array}$ & $\begin{array}{l}78.94 \\
25.51\end{array}$ & $\begin{array}{r}66.43 \\
1.81\end{array}$ & $\begin{array}{c}21.11 \\
0\end{array}$ & $\begin{array}{l}0 \\
0\end{array}$ & $\begin{array}{r}27.97 \\
1.92\end{array}$ & $\begin{array}{c}87.13 \\
0\end{array}$ & $\begin{array}{c}53.03 \\
0\end{array}$ & $\begin{array}{l}0.77 \\
0\end{array}$ \\
\hline
\end{tabular}

The values for the critical VMPC cells are in bold in the table. Cells $\mathrm{I}-4=$ ventromedial prefrontal (VMPC) sector (posterior to anterior); Cell $5=$ medial superior sector; Cells 6-9 = lateral orbital sector (posterior to anterior); Cell $10=$ anterior dorsolateral sector. See legend of Fig. I for more detail. 
0297 (the left hemisphere lesion). The left hemisphere case (0297) was normal in all measured domains. He returned successfully to his job as a rural mail carrier within 1 year after his brain injury (caused by subarachnoid haemorrhage due to rupture of an anterior communicating artery aneurysm), remains in a stable marriage and maintains the same social status as he enjoyed premorbidly. His MMPI-2 profile is normal, he does not have acquired sociopathy, and he performed normally on the IGT. In sharp contrast, the right hemisphere case (1768) was severely impaired in social conduct, emotional processing and personality, and decision-making. He demonstrates severe behavioural problems, including abulia, blunted affect, reduced motivation, distractibility and perseveration, and he has never been able to maintain

Table 3 Social conduct

\begin{tabular}{lllll}
\hline $\begin{array}{l}\text { Participants } \\
\text { (sex/ } \\
\text { hemisphere) }\end{array}$ & $\begin{array}{l}\text { Social } \\
\text { status }\end{array}$ & $\begin{array}{l}\text { Employment } \\
\text { status }\end{array}$ & $\begin{array}{l}\text { Interpersonal } \\
\text { functioning }\end{array}$ & $\begin{array}{l}\text { Overall } \\
\text { change } \\
\text { (magnitude) }\end{array}$ \\
\hline $1652(\mathrm{M} / \mathrm{L})$ & $\mathrm{I}$ & $\mathrm{I}$ & $\mathrm{I}$ & No \\
I589 (M/R) & 3 & 3 & 3 & Yes (severe) \\
$0297(\mathrm{M} / \mathrm{L})$ & $\mathrm{I}$ & $\mathrm{I}$ & $\mathrm{I}$ & No \\
I768 (M/R) & 3 & 3 & 2 & Yes (severe) \\
$2748(\mathrm{~F} / \mathrm{L})$ & 2 & 2 & 2 & Yes (moderate) \\
$2025(\mathrm{~F} / \mathrm{R})$ & $\mathrm{I}$ & $\mathrm{I}$ & 1 & No \\
I80I (F/R) & $\mathrm{I}$ & $\mathrm{I}$ & 1 & No \\
$2310(\mathrm{~F} / \mathrm{R})$ & $\mathrm{I}$ & 2 & 2 & Yes (mild) \\
\hline
\end{tabular}

The extent of change or impairment in various aspects of social conduct was rated on a three-point scale, where I = no change or impairment, 2 = moderate change or impairment, $3=$ severe change or impairment. Overall change was based on a general impression derived from the other three domains, as rendered by clinical neuropsychologists who were naïve as to the hypotheses and objectives of the current study. See text for details. competitive employment following his lesion (he worked successfully as a diesel mechanic prior to his brain injury, which was caused by an infarction in the territory of the anterior cerebral artery). He had an abnormal MMPI-2 profile, with significant elevations on the depression (2) and social introversion (0) scales. He had moderately severe acquired sociopathy and his IGT performance was severely impaired.

Comparison of two women with ventral-mesial lesions. This contrast involved case 2748, who has a left ventral-mesial VMPC lesion, and case 2025, who has a right ventralmesial VMPC lesion (Fig. 2; Table 2). In both cases the polar and anterior VMPC regions are damaged (cells 2-4), and in case 2025 the lesion also damages the posterior VMPC sector (cell 1). [In both cases there is also damage to the lateral orbital region (cells 7-10).] The overall percentage of damage in the critical VMPC cells (1-4) is slightly larger for 2025 (the right hemisphere case). The left hemisphere case (2748) was moderately to severely impaired in social conduct, emotional processing and personality, and decision-making. She worked as a bookkeeper before the onset of her lesion, which was caused by surgical treatment of a left frontal subarachnoid cyst. Afterwards, she became unreliable in her work attendance and was eventually discharged; subsequently, she has not been able to secure and maintain gainful employment. She is impulsive and unpredictable, and suffers from 'moodiness' that has prompted treatment with medication. According to our experimental measurements, she had moderate changes in social conduct and an abnormal MMPI-2 profile, with significant elevations on the hysteria (3) and psychopathy (4) scales. She had moderately severe acquired sociopathy and severely impaired IGT performance. By contrast, the right hemisphere case (2025), whose lesion was caused by subarachnoid haemorrhage due to rupture of an anterior communicating artery aneurysm, was normal in all measured domains. Within several months of the onset of her lesion,

Table 4 Emotional functioning/personality and the IGT

\begin{tabular}{lclll}
\hline Participants (sex/hemisphere) & BDI* & MMPI-2 $^{\dagger}$ & Acquired sociopathy & IGT \\
\hline I652 (M/L) & 2 & Normal & No & Normal \\
I589 (M/R) & 14 & Abnormal (4-6) & Yes (3) & Impaired (3) \\
$0297(\mathrm{M} / \mathrm{L})$ & 3 & Normal & No & Normal \\
$1768(\mathrm{M} / \mathrm{R})$ & 13 & Abnormal (2-0) & Yes (2) & Impaired (3) \\
$2748(\mathrm{~F} / \mathrm{L})$ & 2 & Abnormal (3-4) & Yes (2) & Impaired (3) \\
$2025(\mathrm{~F} / \mathrm{R})$ & 0 & Normal & No & Normal \\
$180 I(\mathrm{~F} / \mathrm{R})$ & 14 & Normal & No & Normal \\
$2310(\mathrm{~F} / \mathrm{R})$ & 0 & Abnormal (4) & Yes (I) & Normal \\
\hline
\end{tabular}

$* \mathrm{BDI}=$ Beck Depression Inventory. Raw scores are provided, and scores $>10$ indicate significant depressive symptomatology.

tMMPI-2 = Minnesota Multiphasic Personality Inventory-2. 'Abnormal' refers to significant elevations (i.e. $T$-scores $>65$ ) on one or more of the 10 clinical scales, and the elevated scales are indicated (see text for further explanation). 'Normal' denotes no clinical scale elevations above $T=65$.

${ }^{\ddagger}$ Acquired sociopathy refers to whether or not the participant met criteria for acquired sociopathy, as derived from data on the lowa Rating Scales of Personality Change. The numbers in parentheses denote degree of severity, where I = mild, $2=$ moderate and 3 = severe.

§Performance on the IGT was classified as normal or impaired using standard criteria. The numbers in parentheses denote magnitude of impairment, where $\mathrm{I}=$ mild, 2 = moderate and $3=$ severe. See text for details. 
she returned to her occupation as a secretary, and she continued to work successfully at that job for many years. She had a normal MMPI-2 profile, no evidence of acquired sociopathy and a flawless performance on the IGT.

\section{Effect of gender, within lesion side}

Comparison of a man and a woman with right ventral lesions. This contrast involved case 1589 and case 2310, a man and woman, respectively, who have right ventral VMPC lesions (Fig. 2; Table 2). In both cases the damage is centred in the mid-section of the medial orbital region (cells 1-3). The percentage involvement of the VMPC cells is somewhat larger in 2310, the woman. As noted above, the man (1589) had severe impairments in social conduct, emotional functioning and personality, and decision-making. The woman (2310), whose lesion was caused by subarachnoid haemorrhage due to rupture of a posterior communicating artery aneurysm, has mild changes in some aspects of social conduct, a slight elevation on the psychopathy scale (4) of the MMPI-2, and she meets criteria for acquired sociopathy (mild in severity). However, she has remained in a long-term, stable marriage following her lesion. Also, her IGT performance was normal. We had noted previously that this case had less pronounced changes compared with other right-sided VMPC cases (all of whom were men), and had speculated as to possible reasons for this (Tranel et al., 2002). In hindsight, and with the light of the current evidence, the parsimonious variable is probably gender.

Comparison of a man and two women with right ventralmesial lesions. This contrast involved case 1768 (a man) and cases 2025 and 1801 (both women). All three cases had damage in all four VMPC cells (1-4), although the percentage involvement in the man (1768) tended to be smaller than that seen in the two women. The man and one of the women (2025) were described earlier; briefly, the man had severe impairments in social conduct, emotional functioning/ personality and decision-making, whereas the woman (2025) was normal in all of these domains. The additional woman case, 1801, also has involvement of the VMPC cells $(1-4)$, generally more extensive than what is seen in the comparison man (1768). Case 1801 sustained a right VMPC lesion at age 45 as a consequence of subarachnoid haemorrhage due to rupture of an anterior communicating artery aneurysm. Within several months of her injury, she was well recovered and able to return successfully to her job as a registered nurse. In fact, she works in an intensive care unit and has been able to remain at this high-pressure job, full time, without difficulty. She has had occasional complaints of depression, and some evidence of emotional lability, but these problems have not interfered with her ability to function well in social, interpersonal and occupational realms. She remains in a stable long-term marriage. Experimental assessment failed to reveal any notable defects in the domains of social conduct, emotional functioning and personality, and decision-making. She had a normal MMPI-2 profile, no evidence of acquired sociopathy and normal performance on the IGT.

Comparison of a woman and a man with left ventral-mesial lesions. This contrast involved case 2748 (a woman) and case 0297 (a man). The woman (2748) has significant damage in the anterior and middle cells (2-4) of the left VMPC region. The man (0297), whose lesion is also in the left hemisphere, has more extensive involvement of the middle VMPC cells (2-4), as well as involvement of the posterior VMPC region (cell 1), not damaged in the woman. The behavioural profiles of these two cases were described earlier; briefly, the woman had moderate to severe impairments in social conduct, emotional functioning/personality and decisionmaking, while the man was entirely normal in all of these domains.

\section{Summary}

Altogether, this series of contrasts allows the conclusion that gender appears to influence the nature of asymmetry in how damage to the left and right sectors of the VMPC leads to defects in social conduct, emotional processing and personality, and decision-making. In men, right-sided VMPC lesions yielded severe defects in these functions; by contrast, very comparable left-sided lesions did not lead to such impairments (cf. 1589 versus 1652; 1768 versus 0297). In women, right-sided VMPC lesions led to relatively few notable changes, by contrast, a left-sided lesion produced significant impairments (cf. 2025, 2310, and 1801 versus 2748). At this point, we cannot rule out the possibility that a large left VMPC lesion in a man might produce some impairment, and we cannot be certain that a small left VMPC lesion in a woman would in fact produce marked defects. We will have to wait for such cases to surface, in order to explore these questions; however, based on our findings so far, we would predict that a man might manifest minimal deficits even with a sizeable left VMPC lesion, while a woman might manifest significant defects even with a small left VMPC lesion.

\section{An additional woman case}

In surveying the cases presented here, a question arises as to whether women are, in general, simply less vulnerable to the types of severe impairments in social conduct, emotional functioning, and decision-making that occur in men, irrespective of lesion side, lesion size and so on (see Discussion section). In the unilateral cases we presented in the current study, the severity of impairments in affected women tended to be less than in affected men. Another way to address this issue would be to determine whether men and women with comparable bilateral VMPC lesions would manifest comparable degrees of impairment, or whether, consistent with the notion of being less vulnerable, women would tend to show less impairment. A search of our database did not turn up well matched bilateral VMPC lesions in men versus women, making it hard to address this question definitively. However, 
we did find one woman case that is informative, and we provide a brief summary of this case here because it is helpful to adjudicate some of the alternative explanations elaborated in the Discussion section.

The case is a woman who had an entirely normal developmental history, with excellent social adjustment, solid academic performance and no family history of psychiatric or psychological maladies. At age 16, she underwent a bifrontal craniotomy for treatment of an anterior communicating artery aneurysm, which resulted in bilateral lesions to the mesial frontal lobes. However, the lesion was very asymmetric and much larger on the left. On the left, the lesion involved all of the mesial orbital and lower mesial prefrontal sectors, from anterior to posterior extents (nearly all of which are marked as cells 1-5 in Fig. 1). The lesion extended superiorly in the mesial sector and laterally into dorsolateral prefrontal cortex. On the right, the lesion was considerably more restricted involving primarily the middle parts of the mesial orbital region (parts of cells 2 and 3 ).

Shortly after the onset of this event, the patient began to exhibit major behavioural problems, which contrasted sharply with her premorbid status. The problems included repeatedly running away, promiscuity, vulgar language, poor personal hygiene and substance abuse. As she grew into early adulthood, her behaviour became even worse. Her decisionmaking, especially in the realm of social interactions, was severely impaired. She failed to develop normal maternal bonds with her children, and she showed a general lack of concern with her condition and deficient responses to emotional situations. She failed to pay bills, bounced cheques, and fraudulently obtained food stamps, with subsequent legal problems. She never held a job for more than a few weeks and showed a consistent lack of motivation.

The patient was brought to our attention by her mother who sought our assistance in a letter that reported 'my daughter is a modern day Phineas P. Gage'. We evaluated the patient when she was 34 years old (the patient is 2313 in our Patient Registry). She is fully right-handed $(+100)$. Conventional neuropsychological evaluation indicated average intellectual abilities (WAIS-III VIQ = 98; PIQ = 98), normal speech and language, and normal perception and attention. Most aspects of memory were intact. She performed normally on the Wisconsin Card Sorting Test, but her Tower of Hanoi performance was impaired. Her MMPI-2 profile was abnormal with the depression (2) and psychopathy (4) scales both elevated ( $T$-scores of 86 and 85 , respectively). She had severe acquired sociopathy on the Iowa Rating Scales of Personality Change and severely impaired performance on the IGT.

In summary, this woman presented with a disturbance of social conduct, emotional functioning and decision-making that is highly reminiscent of the profile that is typically observed in bilateral VMPC patients. Moreover, the severity of the condition was comparable with the prototypical cases reported in the literature, such as patient EVR (Eslinger and Damasio, 1985), and the condition was clearly acquired in an individual who had been developmentally normal before her brain damage. Her condition is, in a nutshell, completely indistinguishable from that described in the most severe bilateral cases in the literature. In the context of the current study, this is an important observation on two counts: (i) it suggests that women are not necessarily less vulnerable to severe disturbances of conduct, emotion and decisionmaking following VMPC damage and (ii) it is at least consistent with the possibility that the left-sided VMPC sector is more critical in women, if one assumes for the sake of argument that the larger left-sided lesion in this case is playing a greater role in the development of her behavioural problems.

\section{Discussion}

Gender-related differences in cognitive abilities, especially verbal legerity (where women tend to have an advantage) and spatial processing (where men tend to have an edge), are well established (even if the sources of these differences remain controversial; see Caplan et al., 1997), and they have received considerable attention in the psychological literature for over a century (e.g. Woolley, 1910; Maccoby and Jacklin, 1974; McGlone, 1980; Hyde et al., 1990; Kimura, 1999). Recently, neuroscience has begun to weigh in on this topic, and there are provocative hints that some gender-related cognitive differences could have neurobiological correlates (e.g. Grabowski et al., 2003; Bolla et al., 2004; Cahill et al., 2004; Njemanze, 2005). For example, Cahill et al. demonstrated that the amygdala's role in the enhancement of memory by emotion is modulated by gender-the right amygdala plays a critical role in men and the left amygdala plays a critical role in women. Bolla et al. reported a parallel result with regard to the prefrontal cortex and decision-making: men demonstrated greater right hemisphere activation during a decision-making task, whereas women demonstrated more left hemisphere activation.

Our study provides preliminary evidence that the asymmetry in the manner in which the left-sided and right-sided sectors of VMPCs subserve functions such as social conduct, emotional processing and decision-making, may be modulated by gender. In men, there is a right-sided bias in this relationship; in women, the reverse is true, and there is a left-sided bias. This conclusion is based on the findings that unilateral damage to the right VMPC produced severe social/emotional and decision-making impairments in men; in women, by contrast, unilateral damage to the right VMPC produced mild deficits at worst, and in some cases did not lead to deficits at all. In contradistinction, damage to the left VMPC produced social/emotional and decision-making impairments in a woman but not the men. And in a post hoc observation, we noted that a woman with a large left VMPC lesion and small right VMPC lesion developed a severe disturbance of social conduct, emotional functioning and decision-making.

It is instructive to examine the literature with an eye towards the way unilateral VMPC damage and gender interact 
to influence outcomes on various emotional processing and decision-making tasks. The message from the literature is that in studies that report deficits associated with unilateral VMPC damage, the participants are almost entirely men and the lesions are mainly right-sided. Again, this pattern is very much in line with our findings, and we do not believe it is a coincidence. The specific evidence is as follows.

Rolls et al. (1994; see also Hornak et al., 1996) reported on 9 patients who had unilateral VMPC lesions and impairments in reversal learning and extinction on simple visual discrimination tests. The authors did not comment on laterality or gender issues; however, not only were most of the unilateral patients right-sided (7/9), but 6 of the 7 unilateral right hemisphere patients were men. Angrilli et al. (1999) described a single case - a man - who had a right orbitofrontal lesion and whose behaviour was remarkably similar to that of patients with bilateral VMPC damage (cf. Damasio et al., 1990). Grafman and colleagues (Gomez-Beldarrain et al., 2004) reported that patients with right prefrontal lesions were impaired on an interpersonally-based economic decision-making task, and the defect tended to be more pronounced with orbital as compared with dorsolateral lesions. Interestingly, of the 15 patients with unilateral right-sided prefrontal lesions, all but three were men. Gender effects were not reported, but this study is consistent with our work, inasmuch as the impaired prefrontal group was comprised nearly entirely of men. [In another study from Grafman's laboratory (Goel et al., 2004), impairments in social reasoning were more severe following left-sided prefrontal lesions, compared with right-sided ones; however, the gender makeup of the left and right prefrontal groups was not reported.] Finally, Manes et al. (2002) presented five patients with unilateral orbitofrontal lesions. The authors reported the 'surprising and important' finding that this group was 'remarkably unimpaired' on several complex decision-making tasks, including the IGT. In four of the patients, two of whom were men, the lesion was on the left, and in one (a woman), the lesion was on the right. The authors do not report specific findings from individual cases, but at least three of these cases are consistent with our current findings, when the factors of gender and laterality are jointly considered-i.e. lack of impairment would be predicted in men with left-sided lesions and women with right-sided lesions.

Our findings do not speak of the important questions of how gender-related asymmetry of prefrontal function would develop, or why this should happen. It could be the case that in men, problem-solving in the social/interpersonal domain is performed in a more holistic, gestalt-type mode, engendering a more 'right-hemisphere' type of strategy. In women, such problem-solving could be performed in a more analytic, verbally-mediated mode, engendering a more 'lefthemisphere' type of strategy. There is a recent parallel for this in the domain of general intelligence, where Njemanze (2005) found that women used a left hemisphere strategy to solve Raven's progressive matrices tasks, whereas men used a right hemisphere strategy (indexed by transcranial Doppler ultrasound). This is an intriguing finding, especially because the matrices tasks require higher-order reasoning and problem-solving strategies that have been linked to prefrontal function in positron emission tomography (Duncan et al., 2000) and functional MRI (Prabhakaran et al., 1997) studies. As far as possible neurobiological mechanisms are concerned, it has been suggested that early exposure to sex hormones might have a lasting effect on problem-solving behaviour, and in both men and women, fluctuations in sex hormones have been associated with changes in cognitive pattern (Kimura, 1996). One might argue that 'cognitive style,' rather than gender differences per se, is the key factor that accounts for asymmetry of VMPC function, but this really begs the question, because cognitive style could itself be a direct consequence of gender-related neurobiological differences.

The question of gender-related differences in functional cerebral laterality has been examined in a number of largesample analyses and meta-analyses. The general wisdom has been that women tend to be less 'lateralized' than men (Harris, 1978; McGlone, 1980; Bryden, 1982); however, gender-related differences are small and account for only a fraction of variance in asymmetry scores (Hiscock et al., 1995; Voyer, 1996). A recent view on this literature emphasized that the strength of the relationship between gender and laterality depends very much on the nature of the 'lateralized' task (Boles, 2005), leaving open the possibility that with regard to domains such as emotional processing, social conduct and decision-making, there could be more pronounced genderrelated differences. Or perhaps there is some validity to the 'reduced asymmetry' story with regard to women-even in our preliminary data, there are hints that the left-right VMPC difference is more striking in men compared with women. In the men, right-sided VMPC damage led to very obvious defects and left-sided damage did not; in women, this pattern (while reversed in direction) was less pronounced. Another factor that could come into play here is that women, in general, might not be as prone to disorders of social conduct as are men-in fact, the DSM-IV Axis II condition of antisocial personality disorder is diagnosed with a 3:1 male-to-female ratio (APA, 2000). The fact that a woman with a VMPC lesion (bilateral but larger on the left) developed a severe disturbance of social conduct argues against an extreme version of this idea-e.g. that woman are not vulnerable to social conduct disturbances-but this could still operate at a population level to yield lower rates (or severities) of social conduct disturbance in women overall (as related to brain dysfunction). The additional woman case also tends to tip us in the direction of favouring a 'reversed asymmetry' explanation as opposed to a 'reduced asymmetry' one, although this is clearly an unresolved question that warrants further investigation.

\section{Acknowledgements}

We thank Kathy Jones and Ruth Henson for help in scheduling the patients, Joel Bruss for assistance with the 
neuroanatomical analyses, and Dr Antonio Damasio and two anonymous reviewers for many helpful comments on the manuscript. This work was supported in part by Program Project Grant P01 NINDS NS19632.

\section{References}

APA. Diagnostic and statistical manual of mental disorders (DSM-IV-TR). 4th edn, Text Revision. Washington, DC: American Psychiatric Association; 2000.

Anderson SW, Barrash J, Bechara A, Tranel D. Impairments of emotion and real world complex behavior following childhood- or adult-onset focal lesions in prefrontal cortex. J Int Neuropsychol Soc. In press.

Angrilli A, Palomba D, Cantagallo A, Maietti A, Stegagno L. Emotional impairment after right orbitofrontal lesion in a patient without cognitive deficits. Neuroreport 1999; 10: 1741-6.

Barrash J, Tranel D, Anderson SW. Acquired personality disturbances associated with bilateral damage to the ventromedial prefrontal region. Dev Neuropsychol 2000; 18: 355-81.

Bechara A, Damasio AR, Damasio H, Anderson SW. Insensitivity to future consequences following damage to human prefrontal cortex. Cognition 1994; 50: 7-15.

Bechara A, Tranel D, Damasio H. Characterization of the decision-making deficit of patients with ventromedial prefrontal cortex lesions. Brain 2000; 123: 2189-202.

Blair RJ, Cipolotti L. Impaired social response reversal: a case of 'acquired sociopathy.' Brain 2000; 123: 1122-41.

Boles DB. A large-sample study of sex differences in functional cerebral lateralization. J Clin Exp Neuropsychol 2005; 27: 759-68.

Bolla KI, Eldreth DA, Matochik JA, Cadet JI. Sex-related differences in a gambling task and its neurological correlates. Cereb Cortex 2004; 14: 1226-32.

Bowman CH, Evans CE, Turnbull OH. Artificial time-constraints on the Iowa Gambling Task: the effects on behavioral performance and subjective experience. Brain Cogn 2005; 57: 21-5.

Bryden MP. Laterality: functional asymmetry in the human brain. New York: Academic Press; 1982.

Cahill L, Uncapher M, Kilpatrick L, Alkire M, Turner J. Sex-related hemispheric lateralization of amygdala function in emotionally influenced memory: an fMRI investigation. Learn Mem 2004; 11: 261-6.

Caplan PJ, Crawford M, Hyde JS, Richardson JT. Gender differences in human cognition. New York: Oxford University Press; 1997.

Damasio AR, Tranel D, Damasio H. Individuals with sociopathic behavior caused by frontal damage fail to respond autonomically to social stimuli. Behav Brain Res 1990; 41: 81-94.

Damasio H. The lesion method in cognitive neuroscience. In: Boller F, Grafman J, editors. Handbook of neuropsychology, 2nd edn, Vol. 1. Amsterdam: Elsevier; 2000. pp. 77-102.

Damasio H, Frank R. Three-dimensional in vivo mapping of brain lesions in humans. Arch Neurol 1992; 49: 137-43.

Duncan J, Seitz RJ, Kolodny J, Bor D, Herzog H, Ahmed A, et al. A neural basis for general intelligence. Science 2000; 289: 457-60.

Eslinger PJ, Damasio AR. Severe disturbance of higher cognition after bilateral frontal lobe ablation: Patient EVR. Neurology 1985; 35: 1731-41.

Frank RJ, Damasio H, Grabowski TJ. Brainvox: an interactive, multimodal, visualization and analysis system for neuroanatomical imaging. Neuroimage 1997; 5: 13-30.
Goel V, Shuren J, Sheesley L, Grafman J. Asymmetrical involvement of frontal lobes in social reasoning. Brain 2004; 127: 783-90.

Gomez-Beldarrain M, Harries C, Garcia-Monco JC, Ballus E, Grafman J. Patients with right frontal lesions are unable to assess and use advice to make predictive judgments. J Cogn Neurosci 2004; 16: 74-89.

Grabowski TJ, Damasio H, Eichhorn GR, Tranel D. Effects of gender on blood flow correlates of naming concrete entities. Neuroimage 2003; 20: 940-54.

Harris LJ. Sex differences in spatial ability: possible environmental, genetic, and neurological factors. In: Kinsbourne M, editor. Asymmetrical function of the brain. Cambridge, UK: Cambridge University Press; 1978. pp. 405-522.

Hiscock M, Israelian M, Inch R, Jacek C, Hiscock-Kalil C. Is there a sex difference in human laterality? II. An exhaustive survey of visual laterality studies from six neuropsychology journals. J Clin Exp Neuropsychol 1995; 17: 590-610.

Hornak J, Rolls ET, Wade D. Face and voice expression identification in patients with emotional and behavioural changes following ventral frontal lobe damage. Neuropsychologia 1996; 34: 247-61.

Hyde JS. Meta-analysis and the psychology of gender differences. Signs J Women Culture Soc 1990; 16: 55-73.

Hyde JS, Fennema E, Lamon SJ. Gender differences in mathematics performance: a meta-analysis. Psychol Bull 1990; 107: 139-55.

Kimura D. Sex, sexual orientation and sex hormones influence human cognitive function. Curr Opin Neurobiol 1996; 6: 259-63.

Kimura D. Sex and cognition. Cambridge, MA: MIT Press; 1999.

Koenigs M, Tranel D. Pseudopsychopathy: a perspective from cognitive neuroscience. In: Zald D, editor. The orbitofrontal cortex. New York: Oxford University Press. In press.

Maccoby EE, Jacklin CN. The psychology of sex differences. Stanford, CA: Stanford University Press; 1974.

Manes F, Sahakian B, Clark L, Rogers R, Antoun N, Aitken M, et al. Decisionmaking processes following damage to the prefrontal cortex. Brain 2002; 125: 624-39.

McGlone J. Sex differences in human brain asymmetry: a critical survey. Behav Brain Sci 1980; 3: 215-63.

Njemanze PC. Cerebral lateralization and general intelligence: gender differences in a transcranial Doppler study. Brain Lang 2005; 92: 234-9.

Prabhakaran V, Smith JA, Desmond JE, Glover GH, Gabrieli JD. Neural substrates of fluid reasoning: an fMRI study of neocortical activation during performance of the Raven's Progressive Matrices Test. Cogn Psychol 1997; 33: 43-63.

Rolls ET, Hornak J, Wade D, McGrath J. Emotion-related learning in patients with social and emotional changes associated with frontal lobe damage. J Neurol Neurosurg Psychiatr 1994; 57: 1518-24.

Tranel D. Emotion, decision-making, and the ventromedial prefrontal cortex. In: Stuss DT, Knight RT, editors. Principles of frontal lobe function. New York: Oxford University Press; 2002. p. 338-53.

Tranel D. Theories of clinical neuropsychology and brain-behavior relationships: Luria and beyond. In: Morgan JE, Ricker JH, editors. Handbook of clinical neuropsychology. Amsterdam: Swets and Zeitlinger. In press.

Tranel D, Bechara A, Denburg NL. Asymmetric functional roles of right and left ventromedial prefrontal cortices in social conduct, decision-making, and emotional processing. Cortex 2002; 38: 589-612.

Voyer D. On the magnitude of laterality effects and sex differences in functional lateralities. Laterality 1996; 1: 51-83.

Woolley HT. A review of the recent literature on the psychology of sex. Psychol Bull 1910; 7: 335-42. 